\title{
Effects of a multimodal rehabilitation program in COVID-19 patients admitted to the Intensive Care Unit:A quasi-experimental study
}

\section{Efectos de un programa de rehabilitación multimodal en pacientes con COVID-19 ingresados en la Unidad de Cuidados Intensivos: Un estudio cuasi-experimental}

DOI

https://doi.org/10.35434/rcmhnaaa.2021.143.1244

\section{ABSTRACT}

Background: Patients with severe COVID-19 evolve to acute respiratory distress syndrome (ARDS) and require management in Intensive Care Units (ICU) where they are exposed to immobilization, immunosuppression, malnutrition, nosocomial infections; may develop ICU Acquired Weakness (ICUAW), which increases with the stay and use of mechanical ventilation (MV). There is evidence of the use of different modalities in rehabilitation to mitigate these effects. Goal: To determine the efficacy of a Multimodal Rehabilitation Program (MRP) in reducing the number of days of mechanical ventilation and stay in patients hospitalized for COVID-19 in ICU, as well as to describe its clinical and hospital characteristics. Material and Methods: An quasi-experimental study was designed, with sequential sampling and without blinding. A control and intervention group was formed, with 32 participants each. A Multimodal Rehabilitation Program (MRP) based on four therapeutic modalities was applied and the intervention was quantified through the use of proposed indicators. Results: The variation in days of ICU stay and days of MV were similar in both groups. The Multimodal Rehabilitation Index (iMR) ranged from 0.1 to 2.7 (mean $=1.2, S D=0.7$ ) and had significance for cut-off points $\leq 0.81$ and $\leq 0.94$ in mortality $(p=0.02)$ and Ventilator-free days at 28 days (VFDs-28) $(p=0.01)$. Conclusions: No statistically significant difference was found in favor of the intervention in terms of days of stay in the ICU and days of MV. Explanatorily, it was reported that iMR was related to (VFDs-28) and mortality in patients with severe COVID-19.

Keywords: Covid-19, Physical medicine and rehabilitation, mechanical ventilation, intensive care unit. (Source: DeCS-BIREME).

\section{RESUMEN}

Introducción: Los pacientes con COVID-19 severo, evolucionan a síndrome de distrés respiratorio agudo (SDRA)y requieren manejo en Unidades de Cuidados Intensivos ( $\mathrm{UCl}$ ) donde están expuestos a inmovilización, inmunosupresión, desnutrición, infecciones nosocomiales; pueden desarrollar Debilidad Adquirida (DAUCI o ICUAW), que se incrementa con la estancia y uso de ventilación mecánica (VM). También se incrementa la mortalidad. Objetivo: Determinar la eficacia de un Programa de Rehabilitación Multimodal (PRM) en la disminución de días de ventilación mecánica y estancia en los pacientes hospitalizados por COVID-19 en UCI, así como describir sus características clínicas y hospitalarias. Material y Métodos: Se diseñó un estudio experimental, de muestreo secuencial y sin cegamiento. Se conformó un grupo control e intervención, con 32 participantes cada uno. Se aplicó un Programa de Rehabilitación Multimodal (PRM) basado en cuatro modalidadesterapéuticas y se cuantificó la intervención a través del uso de indicadores propuestos. Resultados: La variación en días de estancia UCI y días de VM fueron similar en ambos
Ronald Milton Rodríguez-Montoya ${ }^{1, a}$, Julio Santos Hilario-Vargas $^{2, \mathrm{~b}}$, Manuel Enrique Alcántara-Gutti ${ }^{3, c}$

\section{FILIATION}

1. Unidad de Cuidados Intensivos. Hospital Alta Complejidad Virgen de la Puerta. EsSalud. Trujillo. Perú.

2. Departamento de Fisiología. Facultad de Medicina Universidad Nacional de Trujillo. Trujillo. Perú.

3. Hospital Víctor Lazarte Echegaray. EsSalud. Trujillo. Perú.

a. Especialista en Medicina Intensivista.

b. Doctor en Ciencias Biomédicas.

c. Especialista en Medicina Física y Rehabilitación.

ORCID

1. Ronald Milton Rodríguez-Montoya 0000-0003-3395-8859

2. Julio Santos Hilario-Vargas 0000-0002-8656-6843

3. Alcántara-Gutti Manuel Enrique 0000-0003-4004-7738

\section{CORRESPONDENCE}

Manuel Enrique Alcántara-Gutti

Dirección postal: Ca. Los Pétalos 233.Dpto 301. Urbanización Los Rosales de San Andrés.

Teléfono: +51959711458

EMAIL

malcantara@gmail.com

CONFLICTS OF INTEREST

The authors declare that they have no conflicts of interest.

FINANCING

Thisresearchwasfundedbythelnstituto de Evaluación de Tecnologías en Salud e Investigación - IETSI- Seguro Social de Salud del Perú, ESSALUD, through"Premio Kaelin en Ciencias de la Salud-Protocolos de Investigación 2020, Versión Especial de Investigaciones Relacionadas a COVID-19".

\section{ACKNOWLEDGMENT}

To Dr. AleksandarCvetković Vega for reviewing the draft and helping in the preparation of this report.

\section{PEER REVIEW}

Received: 21/06/2021

Accepted: $12 / 10 / 2021$

HOW TO CITE

Rodríguez-Montoya, R., Hilario-Vargas, J., \& Alcántara-Gutti, M. Efectos de un programa de rehabilitación multimodal en pacientes con COVID-19 ingresados en la Unidad de Cuidados Intensivos: Un estudio cuasiexperimental. Revista Del Cuerpo Médico Hospital Nacional Almanzor A g u in a ga A se njo, 2021,14 (3), 272 - 279 https://doi.org/10.35434/rcmhnaaa.2021.143.1244

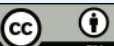

Esta obra está bajo una Licencia Creative

Commons Atribución 4.0 Internacional.

Versión Impresa: ISSN: 2225-5109

Versión Electrónica: ISSN: 2227-4731

Cross Ref. DOI: $10.35434 /$ rcmhnaaa

OJS: https://cmhnaaa.org.pe/ojs 
grupos. El Índice de Rehabilitación Multimodal (iRM)varió desde 0.11 a 2.71 (media= 1.23, DS=0.7) y tuvo significancia para los puntos de corte $\leq 0.81$ y $\leq 0.94$ en mortalidad ( $\mathrm{p}=0.02)$ y días libres de ventilación mecánica al día 28 (DLVM-28) $(\mathrm{p}=0.01)$. Conclusiones: No se halló diferencia estadísticamente significativa a favor de la intervención en cuando a días de estancia en UCl y días de VM. Exploratoriamente se reportó que el iRM tuvo relación con los DLVM-28 y de la mortalidad en pacientes con COVID-19 severo.

Palabras Clave: Covid-19, Medicina Física y Rehabilitación, ventilación mecánica, Unidad de cuidados intensivos. (Fuente: DeCSBIREME).

\section{INTRODUCTION}

Patients with the severe form of COVID-19 develop viral pneumonia with severe hypoxemia that progresses to acute respiratory distress syndrome (ARDS). These patients require management in Intensive Care Units (ICU) where they are exposed to immobilization, immunosuppression, malnutrition or infections, thus increasing mortality and stay in the $I C U^{(1)}$. Rehabilitation is one of the approaches formulated in the face of this situation and the strategies applied have been reinforced or rejected according to the results based on the evidence and the greater understanding of this pandemic ${ }^{(2-6)}$.

One of the most important neuromusculoskeletal alterations in patients with critical illness is Intensive Care Unit Acquired Weakness (ICUAW), which can have a prevalence of up to $70 \%{ }^{(7)}$. Its main clinical manifestation is generalized symmetric weakness, which affects the extremities and can cause tetraplegia $^{(8)}$ and being involved in around $60 \%$ of failures in weaning from Mechanical Ventilation (MV), thus increasing the stay in the ICU and the days of MV, generating a vicious circle ${ }^{(9)}$ with an impact on the length of stay in hospital (LOS), delirium, persistence of post-ICU syndrome and mortality ${ }^{(10)}$. In a report of patients with COVID-19 who required $M V$ in the $I C U$, in a city in Belgium $72 \%$ presented ICUAW on waking up and $52 \%$, upon discharge from the ICU. In addition, patients with weakness stayed longer in days. $\mathrm{ICU}^{(11)}$.

There is scientific evidence in favor of reducing the stay in ICU, use of invasive mechanical ventilation (IMV), increase in ventilator-free days (VFDs) at 28 days (VFDs-28) and functionality at discharge, among others, as a result of different modalities of rehabilitation installed during the critical phase of the disease ${ }^{(12-14)}$. The application of multimodal rehabilitation programs; that is, those that include various interventions such as mobilization, muscular, respiratory and functional training ${ }^{(15)}$, can avoid the impact of ICUAW.

Rehabilitation in critically ill patients with COVID-19 continues to be studied and is based on the different therapy modalities previously studied such as mobilizations, respiratory physiotherapy, patient mobility, bed cycling, electrotherapy, or speech and swallowing therapy ${ }^{(16-19)}$ which have achieved partial consensus regarding its application ${ }^{(20,21)}$. The results of a clinical trial in the United Kingdom based on different rehabilitation modalities, for patients in the ICU due to COVID-19, reported that, at ICU discharge, half of the patients managed to climb into a chair or walk despite the high prevalence by ICUAW ${ }^{(22)}$.

It is necessary to establish rehabilitation models that improve the efficiency of healthcare resources, availability of ICU beds and mechanical ventilators, reducing the impact of critical illness that causes moderate or severe disability, with the consequent individual and social cost and overload in the healthcare system ${ }^{(23)}$. The objective of this research was to determine the effects of a Multimodal Rehabilitation Program (MRP) in patients with COVID-19 admitted to the ICU and to present a working model based on indicators.

\section{MATERIALAND METHODS}

\section{Study design}

Quasi experimental study

\section{Protocol}

The study was based on the protocol formulated by the members of the research team (protocol available at Figshare.com).

\section{Participants}

Patients hospitalized in the ICU of the Hospital de Alta Complejidad "Virgen de la Puerta" - EsSalud (Trujillo, La Libertad, Peru) from August 1 to November 7, 2020. The inclusion criteria were: age over 18 years, use of Invasive mechanical ventilation no longer than 72 hours prior to admission to the ICU. Where excluded, those with some degree of functional dependence, a diagnosis of neuromuscular diseases, tracheostomy carriers or those who had required this procedure during their stay, admission to the ICU with a main diagnosis other than ARDS due to COVID19 or those who were admitted and died before the enrollment.

\section{Allocation}

The coding of the patients was based on the order of admission to the ICU, those with an odd admission number received Usual Care and those with an even number were part of the MRP. The allocation was sequential in a 1: 1 ratio to the MRP or the Usual Care group, with the sample frame being the records of admission to the Intensive Care Service. The total number of participants was 32 for each group.

\section{Procedures}

The MRP assigned to the intervention group was carried out 
six days a week and was in charge of Technologists in Physical and Respiratory Therapy. They were previously instructed in the modalities to be carried out as well as their registration.

\section{Intervention}

\section{- Abbreviate name}

Multimodal Rehabilitation Program (MRP)

\section{- ¿Why?}

MRP was proposed to provide different interventions in ICU patients in order to achieve a shorter stay in the ICU and use of MV. It was based on four modalities $(16,17,24,25)$, which were a) mobilizations of four limbs, b) bed cycling, c) functional training, d) respiratory muscle training.

\section{- ¿What?}

Materials: Was necessary to use material for cycling in bed, elastic bands or therapeutic balloon. For the compilation of the intervention, files were used, which were available in the research protocol. Those responsible for the intervention were trained through audiovisual material and simulated training of data collection sheets, application of criteria for starting and stopping the intervention.

Procedures: Before the start of the interventions, the mechanical ventilation system, filters, safety of the inflatable balloon of the endotracheal tube, invasive access routes and airway permeability were verified daily. The usual care, assigned to the control group, consisted of postural changes including the beginning and end of pronation, permeability of the artificial airway by the service personnel or some routine physiotherapeutic intervention, mainly based on mobilizations.

For the application of the PRM, safety criteria based on a checklist were taken into account to decide to start or continue work with patients $(17,26)$. These were: medical opinion of the patient's stability, heart rate between 40 and 130 beats / min, systolic blood pressure between 90 and 180 $\mathrm{mmHg}$ or mean arterial pressure between 60 and $110 \mathrm{mmHg}$, respiratory rate between 5 and 40 breaths / min, oxygen saturation greater than or equal to $88 \%$, inspired fraction of oxygen less than $60 \%$, positive pressure at the end of expiration (PEEP) less than or equal to $10 \mathrm{cmH} 20$, use of norepinephrine greater than or equal to $0.1 \mathrm{mcg} / \mathrm{kg} / \mathrm{min}$, secured airway, changes in the level of consciousness during activity, appearance of new arrhythmia or that produces symptoms, angina pain, evidence of coronary ischemia, asynchrony with the ventilator, intolerance or rejection by the patient, evidence or suspicion of active bleeding, venous thrombosis deep or pulmonary embolism.

After the verification of security criteria, the different modalities were applied according to the description below $^{(16,17,24,25)}$.

a. Mobilization of the extremities in functional ranges in a series of ten repetitions. When patients presented an adequate level of consciousness, active or active assisted mobilizations were carried out; otherwise, the movement was carried out only by the physiotherapist, that is, passive mobilization.

b. Bed cyclingfor up to ten minutes. This activity was also carried out actively, actively assisted or passively according to the level of consciousness and collaboration of the patient, in the case of patients with adequate collaboration.

c. Functional training, that is, displacements either in your own bed (achieving a sitting position within it or on the edge) by standing or transferring to a chair.

d. Respiratory muscle training, only in patients who were able to obeying instructionsfor the techniques used.

During the first days of stay, the activities were based on mobilization and cycling in bed, later and according to the level of collaboration of the patient, the other modalities of the program were used.

The prone position was a contraindication for bed cycling, functional training and respiratory muscle training, due to the need to comply with the medical prescription of the intensive medicine team. However, the mobilization of the limbs was continued.

When patients were able to obey complex orders or had an indication for ICU discharge (according to the decision of the medical staff of the service), an assessment of muscle strength was performed according to the Medical Research Council scale ${ }^{(27)}$ to establish the diagnosis of ICUAW.

\section{- ¿Who?}

The MRP was carried out by personnel from Medical Technology in Physical and Respiratory Therapy, previously guided and trained by the research team and a specialist in Physical Medicine and Rehabilitation for the application of the MRP.

\section{- ¿What?}

The intervention was carried out in person at the bedside of each patient.

\section{- ¿Where?}

Carried out in the Intensive Care Unit of theHospital de Alta ComplejidadVirgen de la Puerta, Trujillo, La Libertad

\section{- When and how many}

During the period August - November 2020. 657 MRP modalities were carried out

\section{- Adaptations}

The intervention was applied following the proposed protocol. The work modalities could vary in duration according to either the tolerance of the patient or the adverse events triggered.

\section{- How well}

Compliance with the intervention was planned, making use of data collection sheets.

\section{Outcomes}

The variables evaluated in this study were: days of ICU stay, days of invasive mechanical ventilation, ventilator-free days at 28 days (VFDs-28), length of stay in hospital (LOS), muscle strength through the MRC (Medical Research Council) score, mortality, frequency of ICUAW, indicators of IRM and adverse events. 
The use of indicators within the MRP was proposed. These were:

Intensity of Multimodal Rehabilitation according to the "percentage of execution" (IMR\%):The calculation of this variable was carried out by obtaining the percentage of days attended at the MRP with respect to those scheduled for each patient. The number of scheduled care was equal to the number of days of ICU stay, except on Sundays. This indicator was used to estimate the coverage of care.

$$
\text { IMR\% }=\frac{\# \text { MRP attentions executed }}{\text { (days of ICU stay* }}
$$

Intensity of Multimodal Rehabilitation according to the "number of modalities executed per scheduled day" (IMRmscheduled): It was obtained by dividing the total number of modalities executed (mobilization, bed cycling, respiratory muscle training or functional training) between the days programmed for each patient. In other words, the number of days of ICU stay, except on Sundays. This indicator was used to estimate the average of the modalities received according to the scheduled days; that is, during the ICU stay.

$$
\text { IMRm.schduled }=\frac{\text { \#executed modalities }}{\text { days of ICU stay* }}
$$

Multimodal Rehabilitation Index (iMR): Value obtained by multiplying the "Percentage of execution" by the "number of modalities executed per scheduled day" that allowed to measure and compare the concentration of the modalities in each patient.

$$
i M R=I M R \% \times I M R m . \text { scheduled }
$$

\section{Blinding}

No blinding was done.

\section{Sample size}

The entire universe that met the selection criteria during the specified period was included.

\section{Statistical methods}

Measures of central tendency and dispersion were used for quantitative variables and frequencies for categorical variables. Due to the quantitative nature of the variables, days of stay in the ICU, days of mechanical ventilation in the ICU, ventilator-free days at 28 days (VFDs-28), length of stay, and muscle strength, the Mann Whitney $U$ test and T test were used. For categorical variables such as outcome and presence of ICUAW, Pearson's $X^{2}$ test or Fisher's Exact Test were used to make comparisons between groups. Mean Difference (MD) was reported for values that complied with the normal distribution and Relative Risk (RR) for dichotomous variables.

The probable cut-off points for the proposed indicators were subjected to the $\mathrm{X} 2$ test, dichotomizing the outcome variables: days of ICU stay, days of MV, VFDs-28, LOS, muscle strength according to their trend measures central according to its normality distribution. In the case of categorical variables, only their distribution by groups was considered. This analysis was based on the work of Fuentes ${ }^{(28)}$.

The level of significance was established with $p<0.05$. The information was processed in spreadsheets and the SPSS ${ }$ program.

\section{Ethical considerations}

The research protocol was approved by the Specific Ethics Committee for Covid-19 ofComité de ÉticaEspecífico para Covid-19 del Instituto de Evaluación de Tecnologíasen Salud e Investigación (IETSI) - EsSalud and informed consent was obtained from the participants or authorized representatives.

\section{RESULTS.}

From August 1 to November 7, 106 possible participants were registered, which were interchangeably assigned to the control and intervention group. However, within each group, as 29 participants did not meet the selection criteria, they were withdrawn, leaving a total of 77 participants who began follow-up, with 11 and 2 patients withdrawing from the control and intervention group respectively. Figure 1 describes the recruitment process.

The clinical characteristics of the sample, (Table 1), included its comorbidities or risk conditions such as diabetes, obesity, cardiovascular disease - including hypertension-, age over 60 years and others. The age of the participants ranged from 29 to 79 years with an average of $52.5 \pm 14.2$ vs. $56.5 \pm 11.2$ in the control and intervention group respectively. Other data such as the number of associated comorbidities are presented in the same table. A total of 12 participants (18.8\%) did not present comorbidities. Both groups presented infections during the ICU stay.

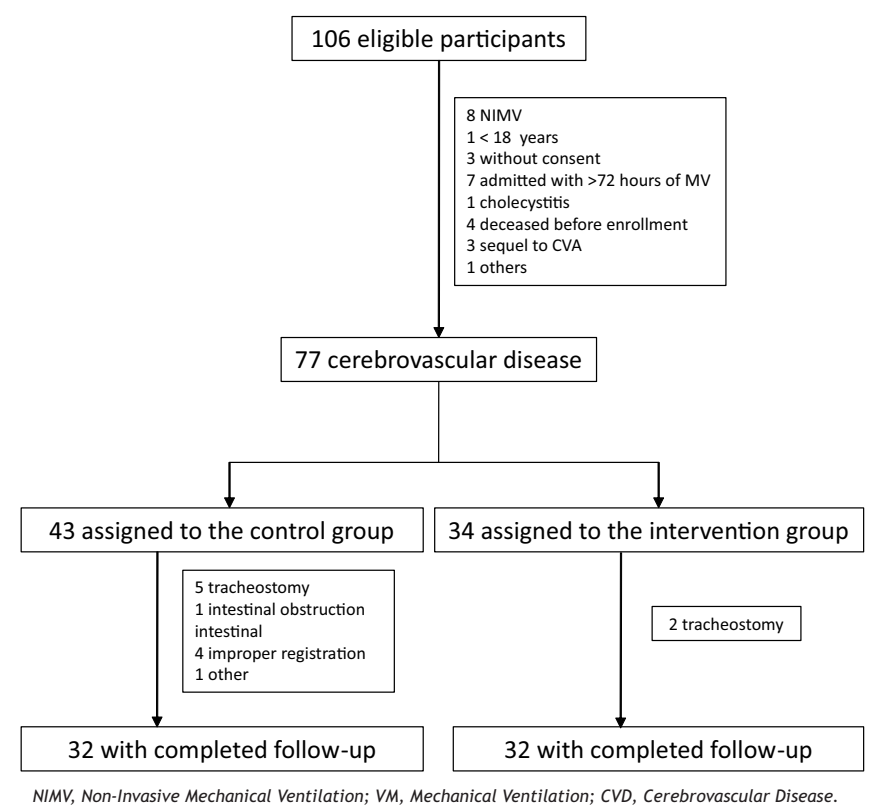

Figure 1.

Selection diagram of study participants 
Table 1. Clinical characteristics of the participants.

\begin{tabular}{lcccc} 
Characteristics & Control group & \multicolumn{3}{c}{ Intervention group } \\
Sex & Men (26) & Women (6) & Men (24) & Women (8) \\
Age (years) & \multicolumn{2}{c}{$52.5 \pm 14.2$} & $56.5 \pm 11.2$ \\
& & & & Relative \\
Comorbidities & Absolute & Relative & Absolute & frequency \\
& frequency & frequency (\%) & frequency & (\%) \\
Diabetes & 4 & 12.5 & 4 & 12.5 \\
Obesity & 14 & 43.8 & 13 & 40.6 \\
Cardiovascular disease* & 8 & 25 & 10 & 31.3 \\
Age> 60 years & 11 & 34.4 & 13 & 40.6 \\
Other comorbidities & 3 & 9.4 & 3 & 9.4 \\
De 1 a 2 comorbidities & 24 & 75 & 20 & 62.5 \\
De 3 a 4 comorbidities & 3 & 9.4 & 5 & 16.6 \\
No comorbidities & 5 & 16.6 & 7 & 21.9 \\
HAls during ICU stay & 15 & 46.9 & 14 & 43.8 \\
\hline
\end{tabular}

*Including Arterial Hypertension, HAls healthcare-associated infections

After comparing the variables of main interest in the control and intervention groups, no statistically significant differences were found in terms of days of ICU stay (control = 13.2 days vs intervention $=18.8$ days, $\mathrm{p}=0.541$ ), days of $\mathrm{MVI}$ in ICU (control $=12.1$ days vs intervention $=14.7$ days, $\mathrm{p}=$ 0.555 ), VFDs-28(control: 5.0 days vs intervention 8.1 days, $p=$ 0.911 ), LOS (control: 25.6 days vs intervention: 27.4 days, $p=$ 0.543), MRC (Medical Research Council) score (control 47.1 points vs intervention 47.2 points, $p=0.954)$. Regarding the qualitative variables, mortality (deceased vs survivors, $\mathrm{p}=$ 1,000 ) and ICUAW (YES vs NO, $p=0.437$ ) did not show statistically significant differences either (Table 2 ).

Furthermore, due to the nature of the intervention, the same variables were analyzed in the surviving participants. No significant differences were found when evaluating the days of stay in the ICU (control = 11.17 days vs. intervention = 13.88 days, $p=0.579$ ), days of $M V I$ in the ICU (control $=9.53$ days vs. 9.55 days, $p=0.588$ ), VFDs-28(control: 18.48 days vs intervention 18.46 days, $p=0.588$ ), LOS (control: 25.85 days vs intervention: 28.35 days, $p=0.545$ ), MRC score (control 47.10 points vs 47.8 intervention points, $p=0.925$ ), presence of ICUAW $(p=0.342)$.

Table 2. Comparison of outcomes by groups in all participants and survivors.

\begin{tabular}{|c|c|c|c|c|c|c|}
\hline \multirow{2}{*}{ Outcome } & \multicolumn{2}{|r|}{ Control group } & \multicolumn{2}{|c|}{ Intervention group } & \multirow{2}{*}{$\mathrm{p}$} & \multirow{2}{*}{$\begin{array}{c}\text { MD(IC 95\%) or RR (IC } \\
95 \%)\end{array}$} \\
\hline & $\mathrm{N}$ & $\begin{array}{l}\text { Position measurement } \pm \text { SD or } \\
\text { Frequency }\end{array}$ & $\mathrm{N}$ & $\begin{array}{c}\text { Position measurement } \pm \text { SD or } \\
\text { Frequency }\end{array}$ & & \\
\hline \multicolumn{7}{|c|}{ Total participants } \\
\hline Days of stay in ICU & 32 & $13,2^{*} \pm 10,2$ & 32 & $18,8^{*} \pm 9,5$ & 0.541 & - \\
\hline Days in VMI ICU & 32 & $12,1^{*} \pm 9,9$ & 32 & $14,7^{*} \pm 9,9$ & 0.555 & - \\
\hline VFDs-28 & 32 & $5,0^{*} \pm 10,5$ & 32 & $8,1^{*} \pm 9,5$ & 0.911 & - \\
\hline Length of stay & 32 & $25,6^{* *} \pm 11,4$ & 32 & $27,4^{* *} \pm 12,3$ & 0.543 & $-1,8(-7,7$ a 4,1$)$ \\
\hline MRC score & 20 & $47,1^{* *} \pm 8,2$ & 21 & $47,2^{* *} \pm 6,9$ & 0.954 & $-1,6(-13,4$ a 10,3$)$ \\
\hline Deceased & & $12(37.5 \%)$ & & $12(37.5 \%)$ & & $1,0(0,5$ a 1,9$)$ \\
\hline \multicolumn{7}{|c|}{ Survivors } \\
\hline Days in VMI ICU & 20 & $9,5^{*} \pm 10,3$ & 20 & $9,6^{*} \pm 7,3$ & 0.588 & - \\
\hline VFDs-28 & 20 & $18,5^{*} \pm 9,1$ & 20 & $18,5^{*} \pm 7,3$ & 0.588 & - \\
\hline Length of stay & 20 & $25,9^{* *} \pm 12,9$ & 20 & $28,4^{* *} \pm 13,0$ & 0.545 & $-2,5(-10,8$ a 5,8$)$ \\
\hline MRC score & 20 & $47,1^{* *} \pm 8,2$ & 20 & $47,8^{* *} \pm 6,5$ & 0.767 & $-0,7(-5,4$ a 4,0$)$ \\
\hline With ICUAW & & $11(55,0 \%)$ & & $8(43,0 \%)$ & & $1,3(0,7$ a 2,7$)$ \\
\hline
\end{tabular}

SD, standard deviation; VMI, Invasive Mechanical Ventilation; MRC, Medical Research Council, ICUAW, Acquired Weakness in ICU, VFDs-28, MV-free days in ICU at day 28; MD, mean difference; RR, Relative Risk.

*Median

${ }^{* *}$ Mean\}

Regarding the other exploratory outcomes, that is, the MRP indicators. The IMR\% was variable from $33.3 \%$ to $100 \%(n=5$ for IMR\% between $33.3 \%$ to $50 \%, n=10$ for IMR\% between $50 \%$ and $75 \%, n=9$ between $75 \%$ and $95 \%$ and $n=8$ with IMR\% equal to $100 \%$ ) the IMRm. schduled was ranged from 0.3 to 2.7 (SD = 0.6 , mean $=1.5)$, and the iMR from 0.1 to $2.7(S D=0.7$, mean $=1.2$ ). The cut-off points established for the indicators were found after selecting the values between the 5\% and 95\% percentiles applying the correction pcorrected $=-3.13 \mathrm{pmin}$ $(1+1.65$ ln $(\mathrm{pmin}))$ where pmin $=p$-value smaller between the probable cutoff points. The iMR was significant for the cut-off points $\leq 0.94(p=0.01)$ and $\leq 0.81(p=0.02)$ in terms of VFDs-28 and mortality respectively (Table 3 ). The other indicators did not have significant cut-off points applying the methodology proposed by Fuentes ${ }^{(28)}$. 
Revista del Cuerpo Médico del HNAAA, Vol 14 (3) - 2021

Table 3. Frequency distribution and comparison between the Multimodal Rehabilitation Index (iMR) with the VFDs28 and mortality.

\begin{tabular}{|c|c|c|c|c|c|}
\hline & & \multicolumn{2}{|c|}{ iMR } & \multicolumn{2}{|l|}{ Total } \\
\hline & & $\leq 0.94$ & $>0.94$ & & $X 2=13,4$ \\
\hline \multirow[t]{2}{*}{ VFDs-28 } & $<8,13$ & 12 & 3 & 15 & pmín. $=0,000253$ \\
\hline & $\geq 8.13$ & 2 & 13 & 15 & pcorrected $=0.01$ \\
\hline \multirow[t]{3}{*}{ Total } & & 14 & 16 & 30 & \\
\hline & & \multicolumn{2}{|c|}{ iMR } & Total & \\
\hline & & $\leq 0.81$ & $>0.81$ & & $X 2=15,2$ \\
\hline \multirow[t]{2}{*}{ Mortality } & Survivors & 2 & 17 & 19 & pmín. = 0,000094 \\
\hline & Deceased & 9 & 2 & 11 & pcorrected $=0.02$ \\
\hline Total & & 11 & 19 & 30 & \\
\hline
\end{tabular}

Of a total of 657 modalities executed in the group that participated in the MRP, 7.6\% $(n=50)$ adverse events considered as mild were reported, because they remitted spontaneously, without medical intervention. These were: intolerance to exercise in $40 \%(n=20)$, alteration of blood pressure in $40 \%(n=20)$, desaturation in $10 \%(n=5)$, alteration of heart rate in $6 \%(n=3)$, altered respiratory rate in $10 \%(n=5)$ and others in $2 \%(n=1)$ (Table 4$)$. The modalities executed were based mainly on mobilization in $54 \%(n=354)$, followed by $29 \%(n=191)$ of bed cycling, $16 \%(n=102)$ of respiratory muscle training and finally $1.5 \%(n=10)$ in functional training.

Table 4. Frequencies of adverse events reported in the Multimodal Rehabilitation Program.

\begin{tabular}{lcc} 
Adverse events & Absolute frequency & Relative frequency (\%) \\
Effort intolerance & 20 & 40 \\
Altered BP & 20 & 40 \\
Desaturation & 5 & 10 \\
HR alteration & 3 & 6 \\
RF alteration & 1 & 2 \\
Others & 1 & 2 \\
\hline Total & 50 & 100 \\
\hline HR, Heart Rate; RR, Respiratory rate & &
\end{tabular}

\section{DISCUSSION}

The general characteristics of the sample included a variety of comorbidities which have been related to increased mortality from severe COVID-19. Only $18.8 \%$ of the sample did not present any comorbidity. In addition, 54.7\% ( $n=35)$ presented infections demonstrated with cultures during their stay in the ICU, a value higher than those reported in other studies that range between $19 \%$ and $49 \%{ }^{(29,30,31)}$. Age also showed variability, and for this reason, there were various conditions that could directly influence mortality.

Despite the fact that in some reports ${ }^{(12,13,14)}$ they find a benefit in favor of rehabilitation in terms of reduction of $\mathrm{MV}$, stay or VFDs-28; In the present work, no significant differences were found between the control and intervention groups. The methodology used in the present work could have influenced the result because elements of the clinical trials, such as randomization and blinding, were not considered; in addition to the broad clinical spectrum of severity in COVID-19. On the other hand, the intervention did not maintain the same dosage in the PRM group. To date, there is no conclusive information on whether rehabilitation modalities in critically ill patients can reduce the duration of these variables ${ }^{(12,32)}$, mainly due to the lack of consensus regarding the modalities used, duration and frequency ${ }^{(33)}$.

ICUAW had no significant association with the intervention. The surviving patients showed a similar frequency in terms of the prevalence of ICUAW (control 55\% vs intervention $40 \% \mathrm{p}=$ 0.34 ) as well as similar averages of MRC score (control 47.1 vs intervention $47.8 \mathrm{p}=0.767)$. These results are similar to those reported in a systematic review with meta-analysis where the intervention did not appear to be related to changes in the incidence of ICUAW or the sum of the MRC score. (34). It should be taken into account that the IMR\% and the iMR varied between $41 \%$ to $100 \%$ and 0.41 to 2.71 respectively, among the survivors, due to the safety criteria applied in the patients that limited the interventions, as well as the condition of sedation that prevents functional training and breathing exercises. Due to the safety of the intervention, already established previously ${ }^{(26)}$, the safety criteria could be broadened, assessing risk-benefit ${ }^{(26,32)}$, allowing a higher percentage of execution and received therapies.

The quantification of the intervention provided in the MRP, through indicators, obtained a significant relationship when comparing the cut-off point of the iMR with the outcome and the VFDs-28 that are considered as outcome measures in ICU services $^{(35)}$. Even the use of VFDs- 28 has been recommended in small sample sizes if it is proposed that the treatment to be investigated simultaneously reduces the duration of ventilation and improves survival outcomes ${ }^{(36)}$. Although mobilization has not been shown to reduce mortality, respiratory therapy activities may have some impact on mortality ${ }^{(37,38)}$. Taking into account that the patients with the lowest iMR were those who presented greater contraindications that limited the intervention; It could be argued that the observed increase in mortality, as well as the few VFDs-28, were possibly due to greater conditions of clinical instability during their stay in the ICU than a direct effect due to the absence of intervention. It cannot be ruled out that those who had higher IRM; that is, those who received a greater concentration of the intervention, could also obtain the established benefits of rehabilitation.

Some of the interventions and care involved in the broad spectrum of respiratory rehabilitation, such as patient positioning ${ }^{(39)}$ could reduce the suspicion of ventilatorassociated pneumonia. However, most of the studies are based on multimodal interventions according to the clinical condition of the patients, a situation that can diversify the intervention and limit adequate conclusions of its effect ${ }^{(37,38)}$, although it was not possible to find studies that mention the efficacy of interventions in populations with superinfections.

The safety of these interventions has also been evaluated taking into account the number of adverse effects, including death, with respect to the total number of sessions performed. In this program, the safety and use of early 
rehabilitation programs for patients admitted to the ICU is established. This aspect was important because commonly a patient admitted to the ICU is considered unstable (high PEEP, pronation, use of vasopressors, high-dose sedoanalgesia, muscle relaxation, among others) and therefore does not receive rehabilitation in the first hours of admission. However, no adverse effects with fatal outcome were reported in this study. Around 15 adverse events that may require interventions have been reported for every 12,200 sessions $^{(32)}$. Regarding the specific use of bed cycling, 5 adverse events have been reported from 3,117 sessions, that is, $0.16 \%^{(40)}$. During the development of this study, $8.37 \%$ adverse events were reported, all mild, remitting spontaneously without pharmacological intervention or changes in ventilatory parameters, which demonstrates the safety of MRP in critically ill patients. No events that required active therapeutic management were reported.

\section{Limitations}

Although the analysis of the outcomes was carried out among the total of participants and also among the survivors, this data could require a more careful interpretation, since the observed mortality constitutes a competitive risk.

The proposed modalities were considered with the same hierarchy. However, there is evidence in favor of superior benefits in terms of the use of respiratory physiotherapy compared to mobilizations.

\section{Conclusions}

No statistically significant differences were found in favor of the application of the MRP in terms of reduction of days of ICU stay and days of mechanical ventilation. In an exploratory way, the use of indicators made it possible to quantify the intervention and it was possible to determine that the iMR was related to the VFDs- 28 and mortality.

\section{Recommendations}

Quantifiable work models that detail the interventions applied in ICUs are required because there are reports that do not specify, for example, the components of respiratory physiotherapy or modes of mobilization.

The security parameters could be expanded, assessing risk benefit, allowing a higher percentage of execution of the recommended modalities.

\section{REFERENCIAS BIBLIOGRÁFICAS}

1. Edwardson S, Cairns C. Nosocomial infections in the ICU. Anaesthesia\&IntensiveCare Medicine. 2019;20(1):14-18. Disponible e https://www.sciencedirect.com/science/article/abs/pii/S1472029 918302509

2. Simpson R, Robinson L. Rehabilitation following critical illness in people with COVID-19 infection. American Journal of Physical Medicine \& Rehabilitation. 2020;1. Disponible en https: / /journals.lww.com/ajpmr/Fulltext/2020/06000/Rehabilitati on_After_Critical_Illness_in_People.5.aspx

3. Negrini F, de Sire A, Andrenelli E, Lazzarini SG, Patrini M, Ceravolo MG, International Multiprofessional Steering Committee of Cochrane Rehabilitation REH-COVER action. Rehabilitation and COVID-19: a rapid living systematic review 2020 by Cochrane Rehabilitation Field. Update as of October 31st, 2020. Eur J PhysRehabil Med. 2021 Feb;57(1):166-170. doi: 10.23736/S1973-9087.20.06723-4. Epub $\begin{array}{llll}2020 & \text { Dec } & 2 & \text { Disponible }\end{array}$ https: / / www. minervamedica.it/en / journals / europamedicophysica/article.php?cod=R33Y2020N05A0642

4. Carda S, Invernizzi M, Bavikatte G, Bensmaïl D, Bianchi F, Deltombe T, Draulans N, Esquenazi A, Francisco GE, Gross R, Jacinto LJ, Pérez M, O'Dell M, Reebye R, Verduzco-Gutierrez M, Wissel J, Molteni F. The role of physical and rehabilitation medicine in the COVID-19 pandemic: The clinician's view. Ann PhysRehabilMed. 2020 Nov;63(6):554-556.

doi: $10.1016 / j . r e h a b .2020 .04 .001$. Disponible en https://www.sciencedirect.com/science/article/abs/pii/S1877065 720300762?via\%3Dihub

5. Thomas P, Baldwin C, Bissett B, Boden I, Gosselink R, Granger C et al. Physiotherapy management for COVID-19 in the acute hospital setting: clinical practice recommendations. Journal of Physiotherapy. 2020;66(2):73-82. doi: 10.1016/j.jphys.2020.03.011. D i s p o n i ble https://www.sciencedirect.com/science/article/pii/S18369553203 0028X?via\%3Dihub

6. Lazzeri M, Lanza A, Bellini R, Bellofiore A, Cecchetto S, Colombo A et al. Respiratory physiotherapy in patients with COVID-19 infection in acute setting: a Position Paper of the Italian Association of Respiratory Physiotherapists (ARIR). Monaldi Archives for Chest Disease. 2020;90(1). Disponible en https://www.monaldiarchives.org/index.php/macd/article/view/1285

7. Taylor C. Intensive care unit acquired weakness. Anaesthesia\& Intensive Care Medicine. 2021, 22 (2): 81-84. doi: $10.1016 / j . m p a i c .2020 .12 .006$. Disponible en https:// www.anaesthesiajournal.co.uk/article/S1472. 0299(20)30271-X/fulltext

8. Rudra R, LinD, Miller B, Du P, Zhang S. Investigating inpatient rehabilitation outcomes of patients with intensive care unit-acquired weakness, and identifying comorbidities associated with unfavorable outcomes. PM R. 2021 Feb 2. doi: 10.1002/pmrj.12565. Disponible en https: / /onlinelibrary.wiley.com/doi/10.1002/pmrj.12565

9. Schweickert W, Hall J. ICU-Acquired Weakness. Chest. $2007 ; 131(5): 1541-1549$. D isponible en https: //journal.chestnet.org/article/S0012-3692(15)316287/fulltext

10. Batt J, Herridge $M$, dos Santos $C$. From skeletal muscle weakness to functional outcomes following critical illness: a translational biology perspective. Thorax. 2019;74(11):1091-1098. Disponible en https: / / thorax.bmj.com/content/74/11/1091.long

11. Van Aerde N, Van den Berghe G, Wilmer A, Gosselink R, Hermans G. COVID-19 Consortium. Intensive care unit acquired muscle weakness in COVID-19 patients. Intensive Care Med. 2020 Nov;46(11):20832085. doi: 10.1007/s00134-020-06244-7. Disponible en https://link.springer.com/article/10.1007/s00134-020-06244-7

12. Zhang L, Hu W, Cai Z, Liu J, Wu J, Deng Y et al. Early mobilization of critically ill patients in the intensive care unit: A systematic review and meta-analysis. PLOS ONE. 2019;14(10):e0223185. Disponible en https: / / journals.plos.org/plosone/article?id=10.1371/journal. pone .0223185

13. Li Z, Zhang X, Wang K, Wen J. Effects of Early Mobilization after Acute Stroke: A Meta-Analysis of Randomized Control Trials. Journal of Stroke and Cerebrovascular Diseases. 2018;27(5):1326-1337. Disponible en https://www.strokejournal.org/article/S10523057(17)30684-5/fulltext

14. Ding N, Zhang Z, Zhang C, Yao L, Yang L, Jiang B et al. What is the optimum time for initiation of early mobilization in mechanically ventilated patients? A network meta-analysis. PLOS ONE. 2019 ; $14(10)$ : e 0223151 . D is ponible e n https: //journals.plos.org/plosone/article?id=10.1371/journal.pone .0223151

15. Verceles A, Wells C, Sorkin J, Terrin M, Beans J, Jenkins T et al. A multimodal rehabilitation program for patients with ICU acquired weakness improves ventilator weaning and discharge home. Journal of Critical Care. 2018;47:204-210. Disponible en https://www.sciencedirect.com/science/article/abs/pii/S0883944 118303113

16. Jones M, Moffatt F, Corner E. Physiotherapy in intensive care. In: Bersten A, Handy J, ed. by. Oh's Intensive Care Manual. 8th ed. Elsevier; 2019. p. 45-57. Disponible en https: / / www.elsevier.com / books/ohs-intensive-caremanual/bersten/978-0-7020-7221-5

17. Nickels M, Aitken L, Barnett A, Walsham J, McPhail S. Acceptability, safety, and feasibility of in-bed cycling with critically ill patients. 
AustralianCriticalCare.2020. Disponible en https://www.sciencedirect.com/science/article/abs/pii/S1036731 420300497

18. Chikhanie Y, Veale D, Schoeffler M, Pépin JL, Verges S, Hérengt F. Effectiveness of pulmonary rehabilitation in COVID-19 respiratory failure patients post-ICU. RespirPhysiolNeurobiol. 2021 May;287:103639. doi: 10.1016/j.resp.2021.103639. Disponible en https://www.sciencedirect.com/science/article/pii/S15699048210 00240?via\%3Dihub

19. Deley G, Laroche D, Quenot JP. Early rehabilitation in ICU for COVID19: what about FES-cycling? Crit Care (2021) 25:94. doi: $10.1186 / \mathrm{s} 13054-021-03526-4$. Disponible en https://ccforum.biomedcentral.com/articles/10.1186/s13054-02103526-4

20. Zeng B, Chen D, Qiu Z, Zhang M, Wang G, Rehabilitation Group of Geriatric Medicine branch of Chinese Medical Association, division of Management of Medical Rehabilitation Institution of Chinese Hospital Association, Rehabilitation Institution Management division of Chinese Rehabilitation Medical Association, division of Rehabilitation Psychology, Chinese Psychological Association, division of Disability Classification Research, Chinese Association of Rehabilitation of Disabled Persons. Expert consensus on protocol of rehabilitation for COVID-19 patients using framework and approaches of WHO International Family Classifications. Aging Med (Milton). 2020 Jul 6;3(2):82-94. doi: 10.1002/agm2.12120. Disponible en https://www.ncbi.nlm.nih.gov/pmc/articles/PMC7338700/

21. Freeman-Sanderson A, Ward EC, Miles A, Netto I, Duncan S, Inamoto Y, McRae J, Pillay N, Skoretz N, Walshe M, Brodsky MB, COVID-19 SLP Global Group. A Consensus Statement for the Management and Rehabilitation of Communication and Swallowing Function in the ICU: A Global Response to COVID-19. Arch Phys Med Rehabil. 2021 May;102(5):835-842. DOI: 10.1016/j.apmr.2020.10.113. Disponible https://www.sciencedirect.com/science/article/pii/S00039993203 12107

22. McWilliams D, Weblin J, Hodson J, Veenith T, Whitehouse T, Snelson C. Rehabilitation Levels in Patients with COVID-19 Admitted to Intensive Care Requiring Invasive Ventilation. An Observational Study. Annals of the American Thoracic Society .2021;18(1):122-129.doi: $10.1513 /$ AnnalsATS.202005-5600C. Disponible enhttps://www.ncbi.nlm.nih.gov/pmc/articles/PMC7780973/

23. Hodgson C, Haines K, Bailey M, Barrett J, Bellomo R, Bucknall T et al. Predictors of return to work in survivors of critical illness. Journal of Critical Care. 2018;48:21-25. Disponible en https://www.sciencedirect.com/science/article/abs/pii/S0883944 118306488

24. Hanekom S, Gosselink R, Dean E, van Aswegen H, Roos R, Ambrosino N et al. The development of a clinical management algorithm for early physical activity and mobilization of critically ill patients: synthesis of evidence and expert opinion and its translation into practice. ClinicalRehabilitation. 2011;25(9):771-787. Disponible en https://journals.sagepub.com/doi/10.1177/0269215510397677

25. Bartels $M$, Bach J. Rehabilitación del paciente con disfunción respiratoria. In: Frontera W, Silver J, Rizzo T, ed. by. Manual de medicina física y rehabilitación. 4th ed. Barcelona: Elsevier; 2020. p. 860-867. Disponible en https://www.elsevier.com/books/manualde-medicina-fisica-y-rehabilitacion/frontera/978-84-9113-634-7

26. Hodgson C, Stiller K, Needham D, Tipping C, Harrold M, Baldwin C et al. Expert consensus and recommendations on safety criteria for active mobilization of mechanically ventilated critically ill adults. Criticalcare. 2014;18 (6). Disponible en https://ccforum.biomedcentral.com/articles/10.1186/s13054-0140658-y

27. Jang $M$, Shin $M$, Shin Y. Pulmonary and Physical Rehabilitation in Critically III Patients. Acute and Critical Care. 2019;34(1):1-13. D is po n i b l e

e $n$ https://www.accjournal.org/journal/view.php?doi=10.4266/acc. 20 19.00444

28. Fuentes SLE. Metodología para la elección de punto de corte óptimo para dicotomizarcovariables continuas. RevCubGen . 2013;7(3):3642. Disponible en https://www. medigraphic.com/cgi- $\mathrm{bin} / \mathrm{new} /$ resumen.cgi?IDARTICULO=53689

29. Neto G, Lo K, Wattoo A, Salacup G, Pelayo J, DeJoy R et al. Bacterial infections and patterns of antibiotic use in patients with COVID-19. Journal of Medical Virology. 2020;93(3):1489-1495. Disponible en https://onlinelibrary.wiley.com/doi/10.1002/jmv.26441

30. Cataldo M, Tetaj N, Selleri M, Marchioni L, Capone A, Caraffa E et al. Incidence of bacterial and fungal bloodstream infections in COVID-19 patients in intensive care: An alarming "collateral effect". Journal of Global Antimicrobial Resistance. 2020;23:290-291.Disponible en https://www.sciencedirect.com/science/article/pii/S22137165203 02654

31. Bardi T, Pintado V, Gomez-Rojo M, Escudero-Sanchez R, AzzamLopez $A$, Diez-Remesal $Y$ et al. Nosocomial infections associated to COVID19 in the intensive care unit: clinical characteristics and outcome. European Journal of Clinical Microbiology \& Infectious Diseases. $2021 ; 40(3): 495-502$. D i s p o n ible e n https: / / link.springer.com/article/10.1007\%2Fs10096-020-04142-w

32. Devlin J, Skrobik Y, Gélinas C, Needham D, Slooter A, Pandharipande P et al. Clinical Practice Guidelines for the Prevention and Management of Pain, Agitation/Sedation, Delirium, Immobility, and Sleep Disruption in Adult Patients in the ICU. CriticalCare Medicine. $2018 ; 46(9)$ : e 825 - e 873 . D i s pon ible e n https://journals.lww.com/ccmjournal/Fulltext/2018/09000/Clinic al Practice Guidelines for the Prevention.29.aspx

33. Masiero S, Zampieri D, Del Felice A. The Place of Early Rehabilitation in Intensive Care Unit for COVID-19. American Journal of Physical Medicine \& Rehabilitation. 2020;99(8):677-678. Disponible en: https: / / journals.Iww.com/ajpmr/Fulltext/2020/08000/The_Place_ of_Early_Rehabilitation_in_Intensive.4.aspx

34. Menges D, Seiler B, Tomonaga Y, Schwenkglenks M, Puhan M, Yebyo H. Systematic early versus late mobilization or standard early mobilization in mechanically ventilated adult ICU patients: systematic review and meta-analysis. CriticalCare. 2021;25(1). D i s p o n b l e e n : https://ccforum.biomedcentral.com/articles/10.1186/s13054-02003446-9

35. Yehya N, Harhay M, Curley M, Schoenfeld D, Reeder R. Reappraisal of Ventilator-Free Days in Critical Care Research. Am J RespirCrit Care Med. 2019:200(7);828-836. Disponible en https: / / www.atsjournals.org/doi/10.1164/rccm.201810-2050CP

36. Schoenfeld S, Bernard G. Statistical evaluation of ventilator-free days as an efficacy measure in clinical trials of treatments for acute respiratory distress syndrome. CriticalCare Medicine. $2002 ; 30(8): 1772-1777$. D is pon ible e n https://journals.lww.com/ccmjournal/Abstract/2002/08000/Statis tical_evaluation_of ventilator_free_days_as.16.aspx

37. Pozuelo-Carrascosa D, Torres-Costoso A, Alvarez-Bueno C, CaveroRedondo I, López Muñoz P, Martínez-Vizcaíno V. Multimodality respiratory physiotherapy reduces mortality but may not prevent ventilator-associated pneumonia or reduce length of stay in the intensive care unit: a systematic review. Journal of Physiotherapy. $2018 ; 64(4): 222-228$. D is p o n ible e n https://www.sciencedirect.com/science/article/pii/S18369553183 01164

38. Wang $M$, Pan $L, H u X$. Chest physiotherapy for the prevention of ventilator-associated pneumonia: A meta-analysis. American Journal of Infection Control. 2019;47(7):755-760. Disponible en https: / /www.ajicjournal.org/article/S0196-6553(18)311787/fulltext

39. Wang L, Li X, Yang Z, Tang X, Yuan Q, Deng L et al. Semi-recumbent position versus supine position for the prevention of ventilatorassociated pneumonia in adults requiring mechanical ventilation. Cochrane Database of Systematic Reviews. 2016. Disponible en https: / /www.cochranelibrary.com/cdsr/doi/10.1002/14651858.CD 009946.pub2/full

40. Takaoka A, Utgikar R, Rochwerg B, Cook D, Kho M. The Efficacy and Safety of In-Intensive Care Unit Leg-Cycle Ergometry in Critically III Adults. A Systematic Review and Meta-analysis. Annals of the American Thoracic Society. 2020;17(10):1289-1307. Disponible en: https: / / www.atsjournals.org/doi/abs/10.1513/AnnalsATS.2020010590C. 